\title{
Microbiome First Approaches in Pain Prevention and Management
}

\author{
Rodney R Dietert ${ }^{1 *}$ and Janice M Dietert ${ }^{2}$ \\ ${ }^{1}$ Department of Microbiology and Immunology, Cornell University, USA \\ ${ }^{2}$ Performance Plus Consulting, Hereford, USA \\ *Corresponding author: Rodney R Dietert, Professor Emeritus of Immunotoxicology, Cornell University, Mailing address: c/o \\ 10035 E. Tristan Dr., Hereford, AZ 85615 USA.
}

To Cite This Article: Rodney R Dietert, Janice M Dietert. Microbiome First Approaches in Pain Prevention and Management. Am J Biomed Sci \& Res. 2021 - 14(2). AJBSR.MS.ID.001976. DOI: 10.34297/AJBSR.2021.14.001976.

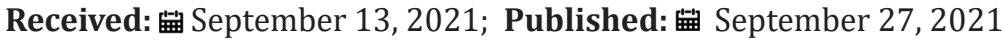

\begin{abstract}
The Microbiome First Initiative aims to facilitate sustainable healthcare by focusing first and foremost on the human holobiont majority, the microbiome. Understanding how the human microbiome affects not only risk of disease but also human perceptions can help individuals thrive and pave the way for a healthy life course. Following a recent review of Microbiome First Medicine the context of health and safety, this present opinion article considers the role of the human microbiome, particularly the gut microbiome, on pain, sensory perceptions, and the prevention and multimodal management of pain. Microbial dysbiosis can be causative of some forms of immune-inflammatory and neurologic pain and the altered human microbiome can lock in the pain while at the same time interfering with analgesic/opioid therapies. Dysbiotic microbiota can make drug treatments less effective and with opioids, the microbes can significantly increase:

1. Opioid tolerance

2. The risk of addiction

3. The likelihood of withdrawal failure.

For these reasons, it is critical to move beyond simply thinking about the microbiome in dealing with pain to considering the microbiome as central in multimodal pain prevention and management strategies. The microbiome is key in any attempts to change physiology, metabolism, systems biology function, and receptor-based perceptions within the human body.
\end{abstract}

Keywords: Holobiont, Pain, Gut microbiome, Inflammation, Depression, Opioids, Addiction, Drug tolerance, Withdrawal, Probiotics, Prebiotics, Microbiome first, Human superorganism, Sustainable Healthcare

Abbreviations: NSAIDs: Non-steroidal anti-inflammatory drugs; NCDs: Noncommunicable diseases and conditions; CR: Colonization resistance; Staph A: Staphyloccocus aureus; PTX: Paclitaxel; CDC: Centers for Disease Control and Prevention; NIEHS: National Institute for Environmental Health Sciences

\section{Introduction}

The Microbiome First initiative is attempting to elevate awareness of the extent to which the human microbiome along with its majority of human genes affects all aspects of human development, health, disease and wellbeing. Including the microbiome in medicine, public health, prevention, nutrition, wellness, and therapeutics is essential if we are to open a path toward sustainable healthcare [1]. In some cases, the human microbiome may play an adjunct role in prevention and therapy while in many cases [e.g., colonization resistance against infections, prevention of noncommunicable diseases and conditions (NCDs)], it should be the first consideration. This opinion article describes the role of the microbiome in pain.

Human microbiota (including commensals and pathobionts) have a central role in pain because they can: cause pain, ablate pain, be damaged by pain medications, inactivate certain pain medications, predispose for opioid addiction, produce opioid tolerance, and affect the success or failure of opioid withdrawal. Given the fact that the human microbiome is not only a target for pain prevention and management but also affects all aspects of pain management, we can no longer afford to manage pain while 
excluding the human microbiome. This article introduces types of pain and the factors that produce them. It also illustrates examples of the connections between the microbiome and pain and the opportunities to include the microbiome-based applications in pain prevention and relief.

\section{Pain}

Chronic pain is one of the most insidious conditions experienced across populations. According to a CDC report on the topic [2], it is one of the most common reasons for seeking medical care. Additionally, it restricts daily activity and can result in opioid dependence and reduced quality of life. A decade ago, pain was touted as a global health priority [3]. In a 2016 estimate by the CDC, 50 million adult Americans carried the burden of chronic pain [2]. Chronic pain rarely exists in isolation. There are frequent comorbidities that arise and increase the burden for those patients who are already dealing with pain. These additional comorbid conditions include but are not limited to depression, anxiety, sleep disturbances, fatigue/lack of energy, and neurocognitive changes [4]. Chronic pain treatment has led to significant problems with the use and misuse of opioids. The problem is significant enough that alternating therapeutics were recently suggested to avoid loss of productivity, addiction, and even opioid-related death [5-7].

The world of pain involves systems biology processes, sensing threshold, and emotions and can be divided into several categories based on location, cause, mechanism and duration (acute vs. chronic). Of the major categories and in keeping with the Rea et al. [8] and Guo et al. [9] reviews, nociceptive pain is usually the result of tissue injury. It is often further subdivided into visceral (a deep internal organ/tissue pain often as a result of damage) and somatic (pain receptors activated in a particular area such as skin, a particular muscle or skeletal region). Bladder or prostate pain would be an example of visceral pain while joint pain from arthritis would be an example of somatic pain. In contrast, inflammatory pain results from immune responses to infections, vaccinations or chronic noncommunicable diseases and conditions (NCDs) driven by inflammation. Infections and vaccinations most commonly result in inflammatory pain.

Finally, neuropathic pain is a category usually caused by nerve irritation or damage. Diabetic peripheral neuropathy would be an example of neuropathic pain [10]. As with the other examples of pain, microbiota can regulate neuropathic pain affecting both the initiation of pain and the thresholds of pain perception [11,12]. Neuropathic pain is considered among the most serious and challenging forms of pain to manage [13]. As Lin et al. point out [11], the power in gut microbiota as regulators of pain including neuropathic pain is that the microbes sit at intersections of immune, neural, endocrine, and metabolic signaling pathways. That complex network has both direct and indirect ways to affect neuropathic pain. The central position of the gut microbiome in the gut-brain axis makes it a preeminent target for pain management strategies.

The microbiome plays a role in virtually all aspects of pain (including initiation and cessation). Pathobionts are one of the primary causes of immune-inflammatory-related pain. One of the most painful infections is caused by the flesh-eating bacteria, Streptococcus pyogenes. Once it penetrates the barrier (e.g., skin), it can result in necrotizing fasciitis. The bacterium takes control of the body's pain sensing neurons, and this causes the infection to be more painful than it would be otherwise [14]. Numerous other bacteria can produce quite painful infections in different body locations [15]. For example, as described by Chiu et al. [16], Staphylococcus aureus (Staph A), a gram-positive bacterial pathogen, can cause painful skin infections while Salmonella enterica and Escherichia coli are responsible for painful gastrointestinal and urinary tract infections.

Staph A can also cause pain via pore forming toxins [17]. Gram negative bacteria, which carry lipopolysaccharide (LPS), can cause direct activation of the TRPA1 ion channel on nociceptors resulting in pain and can also cause signaling via Toll-like receptor 4 (TLR-4). Nociceptors also detect bacterial N-formyl peptides [16]. Fungal pathogens (e.g., Candida albicans) can induce calcium flux in nociceptors and viral pathogens also have some TLR routes to affect neurons [16]. Infectious (or septic) arthritis is a joint pain condition. A variety of pathobionts can be involved including the agent of Lyme disease (Borrelia burgdorferi) [18] and Mycoplasma hominis [19].

The airways are also a target for especially painful infectionrelated diseases. Bronchiectasis is a highly painful airway infection that often results in a chronic condition with lung scarring. It is also comorbid with asthma and can exacerbate an already challenging and painful experience for the patient [20]. While a number of pathobionts have been associated with bronchiectasis including some viruses, two bacteria are of particular interest for their association with disease severity: Pseudomonas aeruginosa [21] and Staph A [22], both having the capacity to form biofilms. It is important to recognize that when pathobionts are involved in pain-inflicting conditions that can become chronic, colonization resistance affords a natural and effective protection against pathobionts within the microbiome. For example, there are several combinations of commensal bacteria that work against carriage of Staph A including Staphylococcus epidermidis [23]. Using Microbiome First applications, we should never miss an opportunity to optimize front-line protection against dangerous pathogens [21].

Vaccinations most commonly resulting in pain appear to be 
those with high ISAR scores. ISARs are inflammation-related solicited adverse reactions including local pain, redness, swelling or induration and systematic fever [24]. High ISAR scores are often indicative of a high immune reaction response to the vaccine [24]. Vaccination induced pain has been associated with autoimmune/ inflammatory syndrome induced by adjuvants (ASIA syndrome). A recent example has been the cases of subacute thyroiditis resulting from the Sinovac Biotech SARS-CoV-2 vaccine [25] as well as from the Oxford-AstraZeneca, United Kingdom vaccine [26]. Examples of pain-associated acute disseminated encephalomyelitis (ADEM) have also resulted from a single dose of the SARS-CoV-2 mRNA vaccine (Moderna COVID-19 Vaccine, Moderna TX, Inc. USA) [27]. Bozkurt et al. [28] reviewed examples of cases of myocarditis with chest pain resulting from both of the mRNA vaccines from PfizerBioNTech and Moderna. Salmon et al. [29] detail five examples of vaccines that passed though safety testing; yet when they were administered, they produced inflammatory-autoimmune-pain syndromes. Two of the vaccine examples are the SARS1 Pandemrix vaccine and narcolepsy, and the human papillomavirus vaccine and complex regional pain syndrome.

With noncommunicable diseases it is clear that microbiome dysbiosis is a significant instigator of these diseases and conditions. This is all the more reason to use microbiome management as a pain reducing strategy. Virtually any NCD can have significant immune-inflicted pain associated with it because they are all driven by underlying inflammation. Additionally, most patients with NCD eventually develop additional comorbid NCDs [1]. Hence, a life-course pain reduction plan should include effective microbiome balance. As an example of the pervasiveness of painful NCDs, musculoskeletal NCDs (e.g., hip and knee osteoarthritis, rheumatoid arthritis, back and neck pain, and gout) number more than 150 different conditions [30] and more than 100 autoimmune conditions [31].
The topic of the capacity of the gut microbiome to regulate pain has been the subject of many recent reviews. Table $1[8,9,11,32$ 51] illustrates and summarizes 23 of these review articles that detail a variety of aspects surrounding pain initiation, detection, biochemistry, and management. As captured among these reviews, there has been an explosion of research on this topic over the past five years. The good news is that the complexity of pain and its perception is largely being deconstructed by knowledge of the gut. As a result, factors controlling the microbiome's bi-directional signaling to the immune system, brain, neurological and endocrine systems are being laid bare and executive pathways determining the initiation and perception of pain are being revealed. Importantly, these review articles also detail the probiotic, prebiotic, and rebiosis strategies that have been used thus far in pain prevention and remediation. Examples are included that focus on pain associated with gastrointestinal issues (ulcerative colitis and irritable bowel), osteoarthritis, probiotics and headaches, post-surgical pain, neurologic and visceral pain, menopausal status, the risk-benefit role of opioids, the connections between microbiota and microglia activation, and gut microbiota as pertains to pain hypersensitivity vs. tolerance.

While a variety of microbiome studies are described within the review articles in Table 1 , the most recent preclinical and clinical trials from the past 2-3 years are highlighted in Table 2 [52-71]. Several areas of activity are notable. First, pain in children (e.g., abdominal) seems to be an area where there is significant interest in the use of pre- and probiotics. Possibly this is because of the hesitancy to immediately prescribe opioids for children. The examples of recent preclinical and clinical trials show that a wide array of pain associated conditions can benefit from microbiome rebiosis. However, it is also clear that additional trials with larger numbers of patients and more standardized probiotic treatments will be helpful in guiding clinical applications.

\begin{tabular}{|c|c|c|c|}
\hline Table 1: Examples of Recent Reviews on Microbiota, Pain, and Pain Management. & Noted Effects/Findings & Reference(s) \\
\hline $\begin{array}{c}\text { Review of cannabinoids and the } \\
\text { microbiome in pain }\end{array}$ & $\begin{array}{c}\text { The review provides a well-designed schematic of the endocannabinoid system and the gut } \\
\text { microbiota-involved pathways to regulate pain. Both are important contributors to pain } \\
\text { regulation, although the interactions between the two are comparatively understudied. The } \\
\text { authors suggest that prebiotics and probiotics can be used as adjunct therapies regarding pain } \\
\text { management and that the microbiome itself is both accessible and adaptable as a route to better } \\
\text { health. }\end{array}$ & [8] \\
\hline $\begin{array}{c}\text { Review of different types of pain, } \\
\text { effect of a variety of probiotics, } \\
\text { and mechanisms of microbiota } \\
\text { regulation of pain as of 2019 }\end{array}$ & $\begin{array}{c}\text { This is a very comprehensive review on microbiota and mechanisms of pain regulation. It } \\
\text { illustrates that ample evidence exists for the effects of the microbiome for several categories } \\
\text { of pain (e.g., visceral, inflammatory, and neuropathic pain, as well as opioid tolerance). Less } \\
\text { information was available for headache pain although some positive-effect studies with } \\
\text { probiotics exist. Pain modification by microbiota can be direct and/or indirect. }\end{array}$ & [9] \\
\hline $\begin{array}{c}\text { Review article on childhood } \\
\text { abdominal pain and different } \\
\text { treatment strategies for childhood } \\
\text { and adolescent abdominal pain. A } \\
\text { section on trials with probiotics } \\
\text { was included in the review. }\end{array}$ & $\begin{array}{c}\text { Sifudies reviewed utilized Lactobacillus reuteri, Lactobacillus GG, Bifidobacteria species, } \\
\text { These were the most common and useful treatments. The authors concluded that while more } \\
\text { comparative studies are needed, probiotics are a reasonable early intervention in pediatrics } \\
\text { particularly for irritable bowel syndrome (IBS). Positive results with probiotics occurred } \\
\text { to a lesser degree for functional abdominal pain disorders (FAPD) and to a lesser extent for } \\
\text { functional dyspepsia (FD). }\end{array}$ & [32] \\
\hline
\end{tabular}


Review on postoperative pain and for Ulcerative colitis bloating and pain

Review on animal models of visceral pain and the microbiome

Review on microbiota and opioids

Review on gut microbiome and osteoarthritis

Review on probiotics and amelioration of rheumatoid arthritis of the microbiome in Irritable Bowel Syndrome

Review of microbiota and somatic pain

Review of microbiota and spinal cord injury

Review of the relationship between microbiota, microglia in the brain, the vagus nerve connection and pain.

Review on gut microbiota, immunity, and pain

Review of the microbiome and regional pain syndrome

Review of microbiota diet and hand osteoarthritis

Review of the opioid system and microbiota dysbiosis

Review of gut microbiota regulating neuropathic pain the gut microbiome

Review on probiotics as adjunct

Review of the clinical management

This is a thorough review covering the various effects of the microbiome on pain. The nature of pain surrounding surgery and recovery is detailed. Direct and indirect interaction with the nervous system is reviewed. The processes through which microbiota induce somatic pain and the probiotics that have been used to reduce pain are discussed. Additionally, the authors conclude that there is justification for targeted use of microbes and prebiotics to enhance the quality of perioperative analgesia and comfort.

Studies with Bifidobacterium, Saccharomyces boulardii, and lactic acid-producing bacteria have shown promise. Additional range finding studies will be useful.

This is a comprehensive review of various animal models for visceral pain with data on microbiota effects for 20 different visceral hypersensitivity procedures. It also describes microbiome assessment and manipulation using germ-free rodents, antibiotic, fecal microbiota transplantation and probiotics.

The review provides a comprehensive look at microbiota and their impact on social behavior. Additionally, it describes how opioids alter gut microbiome composition and how microbiota affect the development of antinociceptive tolerance and opioid-induced hyperalgesia.

The review considers microbiota and osteoarthritis $(\mathrm{OA})$. It provides the pathways through which probiotics work to lesson $\mathrm{OA}$ and illustrates five different trials with probiotics and the impact on both disease outcomes and inflammatory markers.

The review describes the role of microbiota with rheumatoid arthritis (RA). Characteristics of six different categories of bacteria that initiate or prevent RA. Additionally clinical trials with probiotics are described. Probiotics including Lactobacillus casei and Lactobacillus acidophilus were found to be beneficial against RA.

The authors describe the effects of irritable bowel syndrome (IBS) and recommends a multimodal treatment regime that includes probiotics. They point out that probiotics have had success with several parameters connected to IBS. But the same is not true for prebiotics alone to date.

The review discusses the transferability of colon sensitivity with IBS with the transfer of gut microbiota even across species.

The review includes a section on changes in gut microbiota that are associated with spinal injury and contribute to chronic pain. The authors conclude that remodeling of the gut microbiota appears to aid both neurological repair as well as pain reduction.

The article presents information on how microbiota may influence microglia activation and control pain via this pathway.

The review details how gut microbiota work with the immune system to produce inflammation and visceral pain. It also describes the role of microbiota in opioid tolerance.

This review discusses the potential role for the gut microbiota as a potential biomarker for

diagnosis, treatment, and clinical course prediction. Among the pathways considered are effects on the microglia, and other targets via microbial metabolites such as short chain fatty acids. Information is presented on beneficial effects from both prebiotics and probiotic bacteria.

The review focuses on obesity-related changes to microbiota as factors in hand osteroarthritis. Metabolites such as Trimethylamine-N-oxide (TMAO) are discussed as negative factors.

The review covers opioids and the gut-brain axis with some information on the effect of opioids on specific gut microbiota and also probiotic effects on opioid sensitivity/ thresholds.

The article describes the range of pathways through which gut microbiota can regulate neurologic pain. Included are numerous immunological, endocrine, and neurological pathways to regulate pain. Microbiota-based therapies including use of diet, antibiotics, fecal microbiota transplants are presented.

Review of urinary microbiome and Interstitial cystitis/bladder pain syndrome

The article suggests that the urinary microbiome changes with age and that Lactobaccilus content is related to menopausal status. However, these changes do not appear to be related directly to UTIs.

The review discusses several routes through which gut microbiota may directly and indirectly impact migraine headaches. Additionally, studies of potential benefits from probiotic

Review on migraine headache including gut microbiota

administration are discussed including one study using a 14-strain probiotic mixture producing reduced frequency and intensity of headaches with less medication required.

The authors describe recent metabolic analysis of fibromyalgia patients suggesting that they differ in microbiome composition compared with controls. However, it is unclear if the difference is causative. While microbiota can control pain, the authors concluded that more research is needed on the fibromyalgia microbiome before rebiosis approaches are recommended. Dietary
Review of gut microbiota and pertinence in fibromyalgia 


\begin{tabular}{|c|c|c|}
\hline $\begin{array}{c}\text { Review on microbial compound } \\
\text { and visceral pain }\end{array}$ & $\begin{array}{c}\text { This review describes the mechanisms utilized by microbiota (commensals and pathobionts) } \\
\text { to influence visceral pain perception. An emphasis is placed on discerning difference between } \\
\text { transient and chronic pain. The range of microbiota products that affect the nervous system is } \\
\text { discussed by category. The author concluded that microbial products can play a critical role in } \\
\text { the regulation of chronic visceral pain. }\end{array}$ \\
\hline $\begin{array}{c}\text { Review on gut microbiota and } \\
\text { visceral pain }\end{array}$ & $\begin{array}{c}\text { The review covers visceral hypersensitivity and nociception to pain and presents prebiotic and } \\
\text { probiotic results from both preclinical studies in mice and rats and six clinical trials. }\end{array}$ \\
[51] \\
\hline
\end{tabular}

\begin{tabular}{|c|c|c|c|}
\hline Study Group & Microbiota Involved & Effects & Key References \\
\hline $\begin{array}{l}\text { Recurrent abdominal pain in } \\
\text { children }\end{array}$ & $\begin{array}{l}\text { Lactobacillus reuteri DSM } 17938 \\
\text { probiotic administration }\end{array}$ & $\begin{array}{l}\text { Pain was less severe in the probiotic treatment group } \\
\text { and the children had more days without pain during } \\
\text { the study }\end{array}$ & {$[52,53]$} \\
\hline $\begin{array}{l}\text { Recurrent abdominal pain in } \\
\text { children }\end{array}$ & $\begin{array}{l}\text { Lactobacillus rhamnosus GG used in } \\
\text { five trials reviewed }\end{array}$ & $\begin{array}{l}\text { Reduction in both pain frequency and intensity in the } \\
\text { probiotic treatment group }\end{array}$ & [54] \\
\hline $\begin{array}{l}\text { Recurrent abdominal pain in } \\
\text { children }\end{array}$ & $\begin{array}{l}\text { Lactobacillus reuteri DSM } 17938 \\
\text { and Lactobacillus rhamnosus GG } \\
\text { examined as probiotics }\end{array}$ & $\begin{array}{l}\text { L. reuteri DSM } 17938 \text { singificanntly reduced pain } \\
\text { intensity and increased days without pain. No effects } \\
\text { were seen with L.rhamnose GG }\end{array}$ & {$[55]$} \\
\hline $\begin{array}{l}\text { Post-operative pain after upper } \\
\text { limb surgery with peripheral nerve } \\
\text { block }\end{array}$ & $\begin{array}{l}\text { No preoperative manipulation. This } \\
\text { was a comparison of microbiota } \\
\text { associated with low vs. high pain. }\end{array}$ & $\begin{array}{l}\text { In a comparatively small study, a major finding was } \\
\text { that post operative analgesic consumption was } \\
\text { inversely correlated with the Shannon index of } \\
\text { Alpha diversity. Porphyromonas was associated with } \\
\text { acceptable pain levels while a greater abundance of } \\
\text { Lachnospira and Alistipes was observed in patients } \\
\text { with unacceptable pain. }\end{array}$ & [56] \\
\hline $\begin{array}{l}\text { *Gut microbiota basis of } \\
\text { chemotherapeutic-induced pain }\end{array}$ & $\begin{array}{l}\text { Manipulation of gut microbiota } \\
\quad \text { in a mouse model of } \\
\text { chemotherapeutically induced } \\
\text { pain can promote or suppress } \\
\text { inflammation-mediated pain. }\end{array}$ & $\begin{array}{c}\text { Gut microbiotas are critical for the induction of or } \\
\text { protection against chemotherapeutically induced } \\
\text { pain. }\end{array}$ & [57] \\
\hline $\begin{array}{l}\text { *Probiotic formulation tested } \\
\text { to alleviate chemotherapeutic- } \\
\text { induced (Paclitaxel, PTX) peripheral } \\
\text { neuropathy including pain }\end{array}$ & $\begin{array}{l}\text { SLAB51 probiotic formulation } \\
\text { evaluated in in vivo pain model for } \\
\text { action on inflammatory mediators } \\
\text { of pain. }\end{array}$ & $\begin{array}{l}\text { The probiotic treatment reduced both the } \\
\text { inflammatory markers in serum as well as the PTX- } \\
\text { elevated neuropathic pain proteins in the spinal cord. }\end{array}$ & [58] \\
\hline $\begin{array}{c}\text { Probiotics to counteract } \\
\text { chemotherapy (Paclitaxel) induced } \\
\text { neuropathic pain. }\end{array}$ & $\begin{array}{l}\text { Extracts of the probiotic mix } \\
\text { DSF were used to examine the } \\
\text { suppression of chemotherapeutic- } \\
\text { induced, inflammation-mediated } \\
\text { pain. DFS contains L. plantarum } \\
\text { DMS24730, S. thermophilus } \\
\text { DSM24731, B. breve DSM24732, L. } \\
\text { paracasei DSM24733, L. delbrueckii } \\
\text { subsp. Bulgaricus DSM24734, L. } \\
\text { acidophilus DSM24735, B. longum } \\
\text { DSM24736, B. infantis DSM24737. }\end{array}$ & $\begin{array}{l}\text { The probiotic mix mechanistically works against the } \\
\text { upregulation of Interleukin } 8 \text { (IL-8) by interfering } \\
\text { with signaling. IL-8 is produced in response to } \\
\text { sensitive neurons and contributes to the pain } \\
\text { cascade. }\end{array}$ & [59] \\
\hline $\begin{array}{l}\text { Oral lesions and pain from } \\
\text { orthodontic appliances }\end{array}$ & $\begin{array}{l}\text { Lactobacillus brevis } \mathrm{CD} 2 \text { probiotic } \\
\text { treatment }\end{array}$ & Significant reduction in the pain score. & {$[60]$} \\
\hline $\begin{array}{l}\text { Recovery from third mandible } \\
\text { molar (tooth) extraction (surgery) } \\
\text { evaluations using a randomized, } \\
\text { double blind controlled pilot study. }\end{array}$ & $\begin{array}{l}\text { Treatment group had one tablet } \\
\text { two times a day containing a } \\
\text { mixture of Levi Lactobacillus } \\
\text { brevis CECT7480 (KABP-052) and } \\
\text { Lactoplantibacillus plantarum } \\
\text { CECT7481 (KABP-051) or placebo } \\
\text { for the first post-intervention week. }\end{array}$ & $\begin{array}{l}\text { Significantly reduced pain and few eating difficulties } \\
\text { in the group receiving the probiotic. }\end{array}$ & [61] \\
\hline $\begin{array}{l}\text { Chronic widespread pain as often } \\
\text { occurs in fibromyalgia from among } \\
\text { a twin study }\end{array}$ & $\begin{array}{c}\text { The stool microbiome was } \\
\text { analyzed using } 16 \mathrm{~S} \text { rRNA amplicon } \\
\text { sequencing and amplicon sequence } \\
\text { variants. }\end{array}$ & $\begin{array}{l}\text { Alpha diversity was significantly lower in the chronic } \\
\text { widespread pain group vs. the twin controls. The } \\
\text { bacterium Coprococcus comes was significantly } \\
\text { elevated in the group with chronic widespread pain. } \\
\text { A causal role was not established. }\end{array}$ & {$[62]$} \\
\hline
\end{tabular}




\begin{tabular}{|c|c|c|c|}
\hline Symptomatic Hand Osteoarthritis & $\begin{array}{l}\text { This was a study analyzing the } \\
\text { gut microbiome of the population } \\
\text { from an area of China (a portion } \\
\text { of whom had hand osteoarthritis). } \\
\text { No microbiome manipulation was } \\
\text { involved in this population study. }\end{array}$ & $\begin{array}{l}\text { Low relative abundance of Roseburia but high } \\
\text { relative abundance of Bilophila and Desulfovibrio } \\
\text { was found in a population analysis of subjects of the } \\
\text { Xiangya (China) Osteoarthritis Study }\end{array}$ & {$[63]$} \\
\hline $\begin{array}{c}{ }^{*} \text { Manipulated fecal microbiota } \\
\text { transplantation was used between } \\
\text { colitis induced mice and antibiotic } \\
\text { treated recipient rats. The } \\
\text { transplanted microbiota were } \\
\text { manipulated to change donor } \\
\text { microbiota. }\end{array}$ & $\begin{array}{l}\text { Manipulated fecal microbiota } \\
\text { transplants were used to determine } \\
\text { how the thresholds of visceral pain } \\
\text { were controlled by microbiota. }\end{array}$ & $\begin{array}{l}\text { Visceral pain thresholds in the recipient rats were } \\
\text { controlled by spectrum of bacteria transferred and } \\
\text { their short chain fatty acid production profile. }\end{array}$ & {$[64]$} \\
\hline $\begin{array}{l}\text { Probiotics study in Ovariectomized } \\
\text { (OVX) rats }\end{array}$ & $\begin{array}{l}\text { Probiotic administration of } \\
\text { Lactobacillus intestinalis YT2 was } \\
\text { utilized. }\end{array}$ & $\begin{array}{l}\text { The treatment alleviated menopausal symptoms } \\
\text { including reducing pain sensitivity. }\end{array}$ & {$[65]$} \\
\hline $\begin{array}{l}\text { Probiotic treatment of pain } \\
\text { associated with irritable bowel } \\
\text { syndrome }\end{array}$ & $\begin{array}{l}\text { Lactobacillus acidophilus strain } \\
\text { administration }\end{array}$ & $\begin{array}{l}\text { Lactobacillus acidophilus was found to modulate } \\
\text { Intestinal pain and to induce opioid and cannabinoid } \\
\text { receptors. This provides a potentially safer way to } \\
\text { control pain. }\end{array}$ & {$[66]$} \\
\hline $\begin{array}{l}\text { Acyloxyacyl hydrolase is a } \\
\text { host determinant that leads to } \\
\text { microbiota dysbiosis that induces } \\
\text { pelvic pain during interstitial } \\
\text { cystitis. Mice with AOAH and } \\
\text { deficient in it were examined } \\
\text { for pain following microbiota } \\
\text { transplants. }\end{array}$ & $\begin{array}{l}\text { Fecal microbiota transplants were } \\
\text { utilized. }\end{array}$ & $\begin{array}{l}\text { Transplants from } \mathrm{AOAH} \text { deficient mice to } \mathrm{AOAH} \\
\text { adequate mice produced pelvic pain. Fecal } \\
\text { transplants in the reverse direction could protect } \\
\text { against pelvic pain. }\end{array}$ & {$[67,68]$} \\
\hline $\begin{array}{l}\text { Lower disc herniation (LDH) as a } \\
\text { result of inflammation is common } \\
\text { cause of lower back pain }\end{array}$ & Lactobacillus paracasei S16 & $\begin{array}{l}\text { The probiotic elevates the anti-inflammatory } \\
\text { response blunting the immune response that causes } \\
\text { LDH. As a result, it protects against the development } \\
\text { of LDH. }\end{array}$ & {$[69,70]$} \\
\hline Effects of probiotics on migraines & $\begin{array}{c}\text { A randomized double-blind } \\
\text { controlled trial using a } 14 \text { strain } \\
\text { probiotics mixture administered } \\
\text { for } 10 \text { weeks in episodic migrainers } \\
\text { and for } 8 \text { weeks in chronic } \\
\text { migrainers. The probiotic mixture } \\
\text { contained Bacillus subtilis PXN } \\
\text { 21, Bifidobacterium bifidum PXN } \\
\text { 23, Bifidobacterium breve PXN } \\
\text { 25, Bifidobacterium infantis PXN } \\
\text { 27, Bifidobacterium longum PXN } \\
\text { 30, Lactobacillus acidophilus } \\
\text { PXN 35, Lactob. delbrueckii ssp. } \\
\text { bulgaricus PXN 39, Lactob. casei } \\
\text { PXN 37, Lactob. plantarum PXN } 47 \text {, } \\
\text { Lactob. rhamnosus PXN 54, Lactob. } \\
\text { helveticus PXN 45, Lactob. salivarius } \\
\text { PXN 57, Lactococcus lactis ssp. } \\
\text { lactis PXN 63, and Streptococcus } \\
\text { thermophilus PXN } 66 .\end{array}$ & $\begin{array}{l}\text { There was a significant reduction in migraine attacks } \\
\text { in the probiotic vs. placebo groups of both episode } \\
\text { and chronic migraine patients. Additionally, the } \\
\text { probiotic treatment groups (episodic and chronic) } \\
\text { had less severity of attacks and less use of other } \\
\text { drugs vs. the respective placebo groups. Ironically for } \\
\text { the inflammatory markers measured, no treatment } \\
\text { changes were noted despite the positive clinical } \\
\text { outcomes. }\end{array}$ & [71] \\
\hline
\end{tabular}

\section{Microbiota And Analgesics: Opioid Response, Tolerance, Addiction and Withdrawal}

A heavy reliance on pharmaceutical control of pain has several issues. Commonly used painkillers (opioids and non-steroidal anti-inflammatory drugs [NSAIDs]) are among the drugs known to damage the microbiome as discussed by Dietert [1]. While opioids are a category of drugs that have been used in pain management [72], they are also a drug category that has a significant opportunity to cause abuse [73]. This has most recently been seen with regards to fentanyl [74]. Recently, there is a search for multimodal pain management to reduce the reliance on opioids $[75,76]$. The gut microbiome plays essential roles both in the incentive salience end of drug reward behavior and in the pain of withdrawal response 
as was recently reviewed by Ren and Loftipour [77] and GarcíaCabrerizo et al. [78]. Additionally, opioid tolerance is one of the features of a dysbiotic microbiome [79]. This contributes to ever increasing doses of opioids that are required to produce the painkilling effect. It is part of the addiction cycle. There is evidence that rebiosis should be helpful in reversing opioid tolerance connected to microbiome dysbiosis. Zhang et al. [80] found that morphine tolerance established in germ free mice was able to be reversed using probiotics.

A second issue with pharmaceutical control of pain is that NSAIDs have been shown to damage the gut microbiome $[81,82]$. The specific damage impairs colonization resistance and creates increased susceptibility to Clostridioides difficile infection-induced colitis and dysregulates inflammation [83]. Even if microbiota are not used in a multimodal pain control strategy, the microbiome needs to be rebiosed following pharmaceutical therapy. Otherwise, there is a likelihood that the drugs will become less effective, more likely to become addictive and the microbial dysbiosis they create will put the patient at a greater risk of both infections and NCDs.

\section{Conclusions}

This opinion article provides both recent reviews and preclinical and clinical trials to illustrate the benefits of considering the microbiome at every step in the pain preventative and management process. The microbiome and, in particular, the gut microbiome exerts such a pervasive control over systems biology units (e.g., the microimmunosome, the gut-brain axis, the gut-bile axis, the gut-hepatic axis) and metabolism that efforts to manage chronic pain in the absence of managing the microbiome are far more likely to end in a reduced quality of life (either through ongoing pain, depression, and/or drug dependency). A concluding summary of four major benefits to be gained by putting the microbiome first in pain management is shown as follows:

1. Microbiome first action can be useful as a pain preventative. Because microbiota can regulate immune and neurogenic inflammation, there is an opportunity to stop neuronal activation and immune-inflicted tissue damage before lower back pain requires a surgical solution. This is what was found with lumbar injury and avoidance of the need for herniated disc surgery.

2. Inattention to the microbiome presents a long-term problem when it comes to pain. NSAID and opioid treatment for pain causes damage to the gut microbiome. If uncorrected, this creates a vicious cycle of trouble. There is an increase in drug tolerance (less effective drug action per dose) and for opioids there is a greater risk of addiction. Withdrawal is more difficult if the microbiome is in dybiosis. Additionally, the dysbiotic gut microbiome loses colonization resistance increasing the risk of serious pathobiont infections. There is also an increased risk for loss of gut barrier integrity and for the emergence of new NCDs. These new diseases will lead to increased pain and disease burden. None of these complications are necessary when appropriate attention is given to the microbiome.

3. Regular attention to the microbiome has benefits that include and extend beyond pain as an outcome. Better regulation of the body's immune system and inflammatory responses means that a lower prevalence of pain is likely over time. Having a better balance of receptor-driven perception of pain also means that there is a better chance to keep pain as an acute event rather than a lifelong chronic burden. It is a useful step toward sustainable healthcare.

4. Maintaining a healthy microbiome can reduce the comorbidities of pain. Because some NCDs like depression are very common comorbidities of chronic pain, managing the microbiome can help to eliminate these comorbidities. The gut as well as the gut microbiota are potent producers of neuroactive peptides. Balance among the gut microbiota produce improved neurological health. As a result, a healthy, managed gut microbiome enhances resiliency against pain-associated depression.

\section{Conflict of Interest}

The authors declare that there is no conflict of interest.

\section{References}

1. Dietert RR (2021) Microbiome First Medicine in Health and Safety. Biomedicines 9(9): 1099.

2. Dahlhamer J, Lucas J, Zelaya C, Nahin R, Mackeyet S, et al. (2018) Prevalence of Chronic Pain and High-Impact Chronic Pain Among AdultsUnited States, 2016. MMWR Morb Mortal Wkly Rep 67: 1001-1006.

3. Goldberg DS, Mc Gee SJ (2011) Pain as a global public health priority. BMC Public Health 11: 770.

4. Dahan A, Van Velzen M, Niesters M (2014) Comorbidities and the Complexities of Chronic Pain. Anesthesiology 121: 675-677.

5. Fishman MA, Antony AB, Hunter CW, Pope JE, Staats PS, et al. (2021) The Cost of Lost Productivity in an Opioid Utilizing Pain Sample. J Pain Res 14: 2347-2357.

6. Macintyre PE (2021) The opioid epidemic from the acute care hospital front line. Anaesth Intensive Care 2411-2502.

7. Dalton MK, Manful A, Jarman MP, Pisano AJ, Learn PA, et al. (2021) Long-term prescription opioid use among US military service members injured in combat. J Trauma Acute Care Surg. 91(2S Suppl 2): 213-220.

8. Rea K, O' Mahony SM, Cryan JF (2021) High and Mighty? Cannabinoids and the microbiome in pain. Neurobiol Pain 9: 100061

9. Guo R, Chen LH, Xing C, Liu T (2019) Pain regulation by gut microbiota: molecular mechanisms and therapeutic potential. Br J Anaesth 123(5): 637-654.

10. Roth B, Schiro DB, Ohlsson B (2021) Diseases which cause generalized peripheral neuropathy: a systematic review. Scand J Gastroenterol 56(9): 1000-1010. 
11. Lin B, Wang Y, Zhang P, Yuan Y, Zhang Y, et al. (2020) Gut microbiota regulates neuropathic pain: potential mechanisms and therapeutic strategy. J Headache Pain 21(1): 103.

12. Defaye M, Gervason S, Altier C, Berthon JY, Ardid D, et al. (2020) Microbiota: a novel regulator of pain. J Neural Transm (Vienna) 127(4): 445-465.

13. Von Hehn CA, Baron R, Woolf CJ (2012) Deconstructing the neuropathic pain phenotype to reveal neural mechanisms. Neuron 73(4): 638-52.

14. Dance A (2019) Inner Workings: How bacteria cause pain and what that reveals about the role of the nervous system. Proc Natl Acad Sci U S A 116(26): 12584-12586.

15. Van den Boom M, Lennon DR, Crawford H, Freeman J, Castle J, et al. (2021) Microbiology of septic arthritis in young Auckland children. J Paediatr Child Health 31 August 2021.

16. Chiu IM, Pinho-Ribeiro FA, Woolf CJ (2016) Pain and infection: pathogen detection by nociceptors. Pain 157(6): 1192-1193.

17. Blake KJ, Baral P, Voisin T, Lubkin A, Almeida F, et al. (2018) Staphylococcus aureus produces pain through pore-forming toxins and neuronal TRPV1 that is silenced by QX-314. Nat Commun 9(1): 37.

18. Corre C, Coiffier G, Le Goff B, Ferreyra M, Guennic X, et al. (2021) Lyme arthritis in Western Europe: a multicentre retrospective study. Eur J Clin Microbiol Infect Dis 2021 Aug 20.

19. Ali GA, Goravey W, Hamad A, Ibrahim EB, Hasan MR, et al. (2021) An enemy in shadows-Mycoplasma hominis septic arthritis and iliopsoas abscess: Case report and review of the literature. IDCases 26: e01260.

20. Lan G, Huang C, Liu Y, Feng Y, Ni Y, et al. (2021) How does comorbid bronchiectasis affect asthmatic patients? A meta-analysis. J Asthma 58(10): 1314-1328.

21. Fernández-Barat L, Alcaraz-Serrano V, Amaro R, Torres A (2021) Pseudomonas aeruginosa in Bronchiectasis. Semin Respir Crit Care Med 42(4): 587-594.

22. Martins KB, Olmedo DWV, Paz MM, Ramos DF (2021) Staphylococcus aureus and its Effects on the Prognosis of Bronchiectasis. Microb Drug Resist 27(6): 823-834.

23. Glatthardt T, Campos JCM, Chamon RC, de Sá Coimbra TF, Rocha GA, et al. (2020) Small Molecules Produced by Commensal Staphylococcus epidermidis Disrupt Formation of Biofilms by Staphylococcus aureus. Appl Environ Microbiol 2020 86(5): e02539-19.

24. Zhuang CL, Lin ZJ, Bi ZF, Qiu LX, Hu FF, et al. (2021) Inflammation-related adverse reactions following vaccination potentially indicate a stronger immune response. Emerg Microbes Infect 10(1): 365-375.

25. İremli BG, Şendur SN, Ünlütürk U (2021) Three Cases of Subacute Thyroiditis Following SARS-CoV-2 Vaccine: Post-vaccination ASIA Syndrome. J Clin Endocrinol Metab 106(9): 2600-2605.

26. Oyibo SO (2021) Subacute Thyroiditis After Receiving the AdenovirusVectored Vaccine for Coronavirus Disease (COVID-19). Cureus 13(6): e16045.

27. Kania K, Ambrosius W, Kupczy ET, Kozubski W (2021) Acute disseminated encephalomyelitis in a patient vaccinated against SARSCoV-2. Annals Clin Translat Neurol 2021 Sep 4.

28. Bozkurt B, Kamat I, Hotez PJ (2021) Myocarditis With COVID-19 mRNA Vaccines. Circulation 144(6): 471-484.

29. Salmon DA, Lambert PH, Nohynek HM, Gee J, Parashar UD, et al. (2021) Novel vaccine safety issues and areas that would benefit from further research. BMJ Glob Health 6(Suppl 2): e003814.
30. Blyth FM, Briggs AM, Schneider CH, Hoy DG, March LM, et al. (2019) The Global Burden of Musculoskeletal Pain-Where to From Here? Am J Pub Health 109(1): 35-40.

31. National Institute of Environmental Health Sciences (NIEHS) (April 2020) Autoimmune Diseases and Your Environment.

32. Friesen C, Colombo JM, Deacy A, Schurman JV (2021) (accessed Sept. 7,2021 ) An Update on the Assessment and Management of Pediatric Abdominal Pain. Pediatric Health Med Ther 12: 373-393.

33. Brenner D, Shorten GD, O'Mahony SM (2021) Postoperative pain and the gut microbiome. Neurobiol Pain 10: 100070.

34. Agraib LM, Yamani MI, Rayyan YM, Abu-Sneineh AT, Tamimi TA, et al. (2021) The probiotic supplementation role in improving the immune system among people with ulcerative colitis: a narrative review. Drug Metab Pers Ther 2021 Aug 23.

35. West C, Mc Vey Neufeld KA (2021) Animal models of visceral pain and the role of the microbiome. Neurobiol Pain 10: 100064.

36. Eitan S, Madison CA, Kuempel J (2021) The self-serving benefits of being a good host: A role for our micro-inhabitants in shaping opioids' function. Neurosci Biobehav Res 127: 284-295.

37. Arora V, Singh G, O-Sullivan I, Ma K, Natarajan Anbazhagan A, et al. (2021) Gut-microbiota modulation: The impact of thegut-microbiotaon osteoarthritis. Gene 785: 145619.

38. Paul AK, Paul A, Jahan R, Jannat K, Bondhon TA, et al. (2021) Probiotics and Amelioration of Rheumatoid Arthritis: Significant Roles of Lactobacillus casei and Lactobacillus acidophilus. Microorganisms 9(5): 1070 .

39. Andrews CN, Sidani S, Marshall JK (2020) Clinical Management of the Microbiome in Irritable Bowel Syndrome. J Can Assoc Gastroenterol 4(1): 36-43.

40. Tait C, Sayuk GS (2021) The Brain-Gut-Microbiotal Axis: A framework for understanding functional GI illness and their therapeutic interventions. Eur J Intern Med 84: 1-9.

41. Jing Y, Bai F, Yu Y (2021) Spinal cord injury and gut microbiota: A review. Life Sci 266: 118865.

42. Dworsky-Fried Z, Kerr BJ, Taylor AMW (2020) Microbes, microglia, and pain. Neurobiol Pain 7: 100045.

43. Santoni M, Miccini F, Battelli N (2021) Gut microbiota, immunity and pain. Immunology Letters 229: 44-47.

44. Crock LW, Baldridge MT (2020) A role for the microbiota in complex regional pain syndrome? Neurobiol Pain 8: 100054.

45. Silvestre MP, Rodrigues AM, Canhão H, Marques C, Teixeira D, et al. (2020) Cross-Talk between Diet-Associated Dysbiosis and Hand Osteoarthritis. Nutrients 12(11): 3469.

46. Rueda-Ruzafa L, Cruz F, Cardona D, Hone AJ, Molina-Torres G, et al. (2020) Opioid system influences gut-brain axis: Dysbiosis and related alterations. Pharmacol Res 159: 104928.

47. Bhide A, Tailor V, Khullar V (2020) Interstitial cystitis/bladder pain syndrome and recurrent urinary tract infection and the potential role of the urinary microbiome. Post Reprod Health 26(2): 87-90.

48. Arzani M, Jahromi SR, Ghorbani Z, Vahabizad F, Martelletti P, et al. (2020) Gut-brain Axis and migraine headache: a comprehensive review. J Headache Pain 21(1): 15.

49. Minerbi A, Fitzcharles MA (2020) Gut microbiome: pertinence in fibromyalgia. Clin Exp Rheumatol 38 Suppl 123(1): 99-104. 
50. Van Thiel IAM, Botschuijver S, de Jonge WJ, Seppen J (2020) Painful interactions: Microbial compounds and visceral pain. Biochim Biophys Acta Mol Basis Dis 1866(1): 165534.

51. Pusceddu MM, Gareau MG (2018) Visceral pain: gut microbiota, a new hope? J Biomed Sci 25(1): 73.

52. Jadrešin O, Hojsak I, Mišak Z, Kekez AJ, Trbojević T, et al. (2017) Lactobacillus reuteri DSM 17938 in the Treatment of Functional Abdominal Pain in Children: RCT Study. J Pediatr Gastroenterol Nutr 64(6): 925-929.

53. Jadrešin O, Sila S, Trivić I, Mišak Z, Kolaček S, et al. (2020) Lactobacillus reuteri DSM 17938 is effective in the treatment of functional abdominal pain in children: Results of the double-blind randomized study. Clin Nutr 39(12): 3645-3651.

54. Newlove-Delgado T, Abbott RA, Martin AE (2019) Probiotics for Children with Recurrent Abdominal Pain. JAMA Pediatr 173(2): 183-184.

55. Trivić I, Niseteo T, Jadrešin 0, Hojsak I (2021) Use of probiotics in the treatment of functional abdominal pain in children-systematic review and meta-analysis. Eur J Pediatr 180(2): 339-351.

56. Brenner D, Cherry P, Switzer T, Butt I, Stanton C, et al. (2021) Pain after upper limb surgery under peripheral nerve block is associated with gut microbiome composition and diversity. Neurobiol Pain 10: 10072.

57. Shen S, Lim G, You Z, Ding W, Huang P, et al. (2017) Gut microbiota is critical for the induction of chemotherapy-induced pain. Nat Neurosci 20(9): 1213-1216.

58. Cuozzo M, Castelli V, Avagliano C, Cimini A, d'Angelo M, et al. (2021) Effects of Chronic Oral Probiotic Treatment in Paclitaxel-Induced Neuropathic Pain. Biomedicines 9(4): 346.

59. Castelli V, Palumbo P, d'Angelo M, Moorthy NK, Antonosante A, et al. (2018) Probiotic DSF counteracts chemotherapy induced neuropathic pain. Oncotarget 9(46): 27998-28008.

60. Silva NLNV, Della Bona A, Cardoso M, Callegari-Jacques SM, Fornari F, et al. (2021) Lactobacillus brevis CD2 attenuates traumatic oral lesions induced by fixed orthodontic appliance: A randomized phase 2 trial. Orthod Craniofac Res 24(3): 379-385.

61. Ferrés-Amat E, Espadaler-Mazo J, Calvo-Guirado JL, Ferrés-Amat E, Mareque-Bueno J, et al. (2020) Probiotics diminish the post-operatory pain following mandibular third molar extraction: a randomised doubleblind controlled trial (pilot study). Benef Microbes 11(7): 631-639.

62. Freidin MB, Stalteri MA, Wells PM, Lachance G, Baleanu AF, et al. (2021) An association between chronic widespread pain and the gut microbiome. Rheumatology (Oxford) 60(8): 3727-3737

63. Wei J, Zhang C, Zhang Y, Zhang W, Doherty M, et al. (2021) Between Gut Microbiota and Symptomatic Hand Osteoarthritis: Data from the Xiangya Osteoarthritis Study. Arthritis Rheumatol 73(9): 1656-1662.

64. Lucarini E, Di Pilato V, Parisio C, Micheli L, Toti A, et al. (2021) Visceral sensitivity modulation by faecal microbiota transplantation: the active role of gut bacteria in pain persistence. Pain 2021 Aug 13.

65. Lim EY, Song EJ, Kim JG, Jung SY, Lee SY, et al. (2021) Lactobacillus intestinalis YT2 restores the gut microbiota and improves menopausal symptoms in ovariectomized rats. Benef Microbes 1-14.

66. Rousseaux C, Thuru X, Gelot A, Barnich N, Neut C, et al. (2007) Lactobacillus Acidophilus Modulates Intestinal Pain and Induces Opioid and Cannabinoid Receptors. Nat Med 13(1): 35-37.

67. Yang W, Yaggie RE, Schaeffer AJ, Klumpp DJ (2020) AOAH remodels arachidonic acid-containing phospholipid pools in a model of interstitial cystitis pain: A MAPP Network study. PLoS One 15(9): e0235384.
68. Rahman-Enyart A, Yang W, Yaggie RE, White BA, Welge M, et al. (2021) Acyloxyacyl hydrolase is a host determinant of gut microbiome-mediated pelvic pain. Am J Physiol Regul Integr Comp Physiol. 321(3): R396-R412.

69. Cunha C, Silva AJ, Pereira P, Vaz R, Gonçalves RM, et al. (2018) The inflammatory response in the regression of lumbar disc herniation. Arthritis Res Ther 20(1): 251

70. Wang Z, Wu H, Chen Y, Chen H, Wang X, et al. (2021) Lactobacillus paracasei S16 Alleviates Lumbar Disc Herniation by Modulating Inflammation Response and Gut Microbiota. Front Nutr 8: 701644.

71. Martami F, Togha M, Seifishahpar M, Ghorbani Z, Ansari H, et al. (2019) The effects of a multispecies probiotic supplement on inflammatory markers and episodic and chronic migraine characteristics: A randomized double-blind controlled trial. Cephalalgia 39(7): 841-853.

72. Rosenblum A, Marsch LA, Joseph H, Portenoy RK (2008) Opioids and the treatment of chronic pain: controversies, current status, and future directions. Exp Clin Psychopharmacol 16(5): 405-416.

73. Meshberg-Cohen S, Ross Mac Lean R, Schnakenberg Martin AM, Sofuoglu M, Petrakis I, et al. (2021) Treatment outcomes in individuals diagnosed with comorbid opioid use disorder and posttraumatic stress disorder: A review. Addict Behav 122: 107026.

74. Arendt F (2021) The Opioid-Overdose Crisis and Fentanyl: The Role of Online Information Seeking via Internet Search Engines. Health Commun 36(10): 1148-1154.

75. Delle JM, Gazley C (2021) Advocating for Multimodal Pain Management and Reducing the Need for Opioids in the Acute and Chronic Pain Setting. Nurs Clin North Am 56(3): 357-367.

76. Powers MB, Carl E, Levihn-Coon A, Van Veldhuizen M, Caven A, et al. (2021) Nonpharmacologic Pain Management Among Hospitalized Inpatients: A Randomized Waitlist-Controlled Trial of Standard Virtual Reality (CGI VR) Versus Video Capture VR (360 degrees 3D/Stereoscopic Video Capture VR). Clin J Pain 37(9): 678-687.

77. Ren M, Lotfipour S (2020) The role of the gut microbiome in opioid use. Behav Pharmacol 31(2\&3): 113-121.

78. García-Cabrerizo R, Carbia C, O Riordan KJ, Schellekens H, Cryan JF, et al. (2021) Microbiota-gut-brain axis as a regulator of reward processes. J Neurochem 157(5): 1495-1524.

79. Akbarali HI, Dewey WL (2019) Gastrointestinal motility, dysbiosis and opioid-induced tolerance: is there a link? Nat Rev Gastroenterol Hepatol 16(6): 323-324.

80. Zhang L, Meng J, Ban Y, Jalodia R, Chupikova I, et al. (2019) Morphine tolerance is attenuated in germfree mice and reversed by probiotics, implicating the role of gut microbiome. Proc Natl Acad Sci U S A 116(27): 13523-13532.

81. Rogers MAM, Aronoff DM (2016) The influence of non-steroidal antiinflammatory drugs on the gut microbiome. Clin Microbiol Infect 22(2): 178.e1-178.e9.

82. Le Bastard Q, Berthelot L, Soulillou JP, Montassier E (2021) Impact of non-antibiotic drugs on the human intestinal microbiome. Expert Rev Mol Diagn 15: 1-14.

83. Maseda D, Zackular JP, Trindade B, Kirk L, Lising Roxas J, et al. (2019) Nonsteroidal Anti-inflammatory Drugs Alter the Microbiota and Exacerbate Clostridium difficile Colitis while Dysregulating the Inflammatory Response. mBio 10(1): e02282-18. 